\title{
The Workaholism Analysis Questionnaire: Emphasizing Work-Life Imbalance and Addiction in the Measurement of Workaholism
}

\author{
Shahnaz Aziz \\ Ben Uhrich \\ Karl L. Wuensch \\ Brian Swords \\ East Carolina University \\ Author's Notes
}

Correspondence concerning this article should be sent to Dr. Shahnaz Aziz, Associate Professor, Department of Psychology, Mail Stop 565, East Carolina University, Greenville, NC, 27858-4353. Phone: 252-328-1379. Fax: 252-328-6283. Electronic mail may be sent to azizs@ecu.edu

\begin{abstract}
A new measure of workaholism, the Workaholism Analysis Questionnaire (WAQ), was created and validated in a heterogeneous sample of working professionals. The WAQ demonstrated strong internal reliability, convergent validity, concurrent validity, discriminant validity, and content validity. This is the first study to create a measure of workaholism that was psychometrically tested on a heterogeneous working population. Furthermore, the WAQ is the first measure to define workaholism more broadly and provide a more comprehensive assessment by including items that directly tap into work-life imbalance, a common symptom of workaholism and other addictive disorders.
\end{abstract}

Workaholism is a colloquial term used in the popular press, on websites, and in the research literature to describe people who are addicted to work (Oates, 1971). Unlike mere hard workers, workaholics are characterized by a combination of long work hours, intrinsic work motivation, and "emotional rushes" from working hard (Bonebright, Clay, \& Ankenmann, 2000). Oates described workaholism as "the compulsion or the uncontrollable need to work incessantly" (p. 11), implying workaholics have an intense internal work drive. Satisfaction is derived only from work, while other areas of life (e.g., health, leisure activities, relationships) are neglected (Robinson, 1996; Snir \& Harpaz, 2009). Excessive working is derived from an addiction, including obsessive-compulsive tendencies, whereby the enhanced necessity to work impedes multiple life functions (McMillan, O'Driscoll, Michael, Marsh, \& Brady, 2001). Therefore, researchers increasingly agree on qualifying workaholism as a work addiction (Griffiths, 2005).

Researchers have failed to agree on a unified definition of workaholism (Buelens \& Poelmans, 2004; Harpaz \& Snir, 2003; Scott, Moore, \& Miceli, 1997) and the existing measures are often criticized for lack of validity and reliability (Ersoy-Kart, 2005; McMillan, Brady, O'Driscoll, \& Marsh, 2002). In the current study, workaholism is conceptualized as an addiction characterized by an intense work drive that leads to neglect of other interests and negative consequences. In agreement with this definition, work drive and work-life balance serve as the foundation of a new measure of workaholism, the Work Analysis Questionnaire (WAQ). The WAQ was created and validated to expand upon the efforts of others in developing an instrument that can be effective in identifying workaholism, by studying samples more 
representative of the general population of workers, and to serve as an assessment tool for future clinical studies studying the influence of workaholism on human health.

\section{Past Workaholism Measures}

The Workaholism Battery (WorkBat; Spence \& Robbins, 1992) and the Work Addiction Risk Test (WART; Robinson, 1989) are the two most widely used measures of workaholism. The WorkBat consists of three facets (i.e., work involvement, work drive, and work enjoyment; McMillan et al., 2002). Work involvement is psychological involvement with work, work drive is the internal pressure to work, and work enjoyment is the degree of gratification from working. Spence and Robbins conceptualized the workaholic as high on work involvement, high on work drive, and low on work enjoyment. Despite the WorkBat's contribution to the workaholism literature, it has been criticized for problems regarding its validity. One major concern is that it was created and psychometrically tested using a homogenous population of social workers (Spence \& Robbins, 1992). Researchers have argued that this participant pool is not representative of the general population, possibly causing generalizability issues for this measure (McMillan et al., 2002). A second major concern for the WorkBat is the instability of its factor structure. McMillan et al. (2002) retested the WorkBat with a heterogeneous sample of 320 participants. They found: 1) work involvement had weak convergent validity; 2) $33 \%$ of the participants did not fit into a particular worker type; and 3) a two-factor model (work enjoyment and work drive). Other studies have also eliminated the work involvement facet, finding it to consistently be a misfit in the model, thus supporting the two-factor solution (Andreassen, Ursin, \& Eriksen, 2007; Burke, Richardsen, \& Martinussen, 2002; Ersoy-Kart, 2005; Kanai, Wakabayashi, \& Fling, 1996).

Robinson (1989), the developer of the WART, defines workaholism as "the overindulgence in and preoccupation with work, often to the exclusion and detriment of the workaholic's health, intimate relationships, and participation in child rearing" (Flowers \& Robinson, 2002; p. 517). The WART measures workaholism according to Robinson's definition and it has been regarded as a more global instrument than the WorkBat (Brady, Vodanovich, \& Rotunda, 2008). Although the WART is a considerable addition to the field of workaholism, it too has been critiqued for similar validity problems as the WorkBat. The first primary issue is that the WART was developed and validated using homogenous samples of either undergraduates or members of Workaholics Anonymous (McMillan et al., 2001), which do not represent the general population. Another primary issue for the WART is its instable factor structure. Flowers and Robinson (2002) conducted a principle components analysis on the WART and found it to be comprised of five factors, three of which validly differentiated workaholics from nonworkaholics (i.e., compulsive tendencies, control, and impaired communication/self-absorption) - this three factor structure has been replicated in other studies (Clarke, Lelchook, \& Taylor, 2010). Taris, Schaufeli, and Verhoeven (2005) called for reducing the WART to just the Compulsive Tendencies subscale, arguing that it adequately represents workaholism and has considerable overlap with the entire WART on correlates of workaholism. Since the WART's factor structure has proven unstable, we followed Brady et al.'s (2008) recommendation to treat the WART as a unidimensional measure in the current study.

\section{Workaholism and Organizational Commitment}

Organizational commitment is a complex, multifaceted construct that was included in the study to establish both discriminant and concurrent validity. Allen and Meyer's (1990) paradigm is considered the most widely accepted model of organizational commitment and includes three dimensions: 1)

Continuance commitment (CC), which is the fear of losing "side-bets" one has accrued while working for an organization and a perceived lack of alternatives to the current employment situation (Becker, 1960); 2) Affective commitment (AC), which is when one is emotionally attached to and identifies with the organization (Porter, Steers, Mowday, \& Boulian, 1974); and 3) Normative commitment (NC), which is when one feels morally obligated to stay with the organization (Allen \& Meyer, 1990). 
Workaholism is expected to have varying relationships with the subscales of organizational commitment. The critical distinction between workaholism and $\mathrm{AC}$ is that workaholism is defined by intense work behavior, whereas $\mathrm{AC}$ is affective in nature. $\mathrm{AC}$ increases through positive work experiences and varies depending on the organization the employee works for, but the compulsive work drive of workaholics exists regardless of how they feel about the organization. Furthermore, NC is strongly related to AC and both correlate with the same attitude-based variables (e.g., organizational support, Allen \& Meyer, 1990; and job satisfaction, Hackett, Bycio, \& Hausdorf, 1994). Bergman (2006) suggests NC may be a consequence of high AC. This strong connection to AC suggests divergence between $\mathrm{NC}$ and workaholism.

On the other hand, $\mathrm{CC}$ is strengthened when employees feel they may lose benefits upon leaving the organization or perceive a lack of alternatives to their current employment situation. Scott et al. (1997) explain why achievement-oriented workaholism can specifically increase CC, stating "achievementoriented workaholics who have attained their goals may possess substantial organizational 'side bets,' which can lead to organizational commitment" (p. 306). Further, workaholics generally have a low selfesteem (Ng, Sorensen, \& Feldman, 2007; Porter, 1996), a characteristic often coupled with an external locus of control. People with an external locus of control tend to perceive fewer alternatives to their current employment situation than those with an internal locus of control (Spector, 1982); thus, workaholics should have higher CC because their low self-esteem causes them to perceive fewer alternatives to their current employment situation.

\section{Workaholism and Obsessive-Compulsive Personality Disorder}

Obsessive-compulsive personality disorder (OCPD) was included in the study to establish concurrent validity. The DSM-IV-TR (American Psychiatric Association, 2000) defines OCPD as "a pervasive pattern of preoccupation with orderliness, perfectionism, and mental and interpersonal control, at the expense of flexibility, openness, and efficiency" (p. 725). The conceptual ties between workaholism and OCPD are strongly rooted in the academic literature. OCPD is typically deemed an antecedent of workaholism (Naughton, 1987; Ng et al., 2007). Furthermore, Scott et al. (1997) conceptualized three types of workaholism, two of which incorporate obsessive-compulsive characteristics (i.e., the compulsive-dependent workaholic and the perfectionist workaholic), showing how similar workaholism is to OCPD in both its nature and expression.

OCPD has also been linked to workaholism in the empirical literature (Aziz, Adkins, Walker, \& Wuensch, 2010; McMillan et al., 2002). Burke and Fiksenbaum (2009a) empirically linked work drive to obsessive-compulsive behaviors and suggest that work drive may have the strongest relationship with obsessive-compulsive behavior. Samuel and Widiger (2010) investigated the temperament and trait correlates of OCPD using the Schedule for Adaptive and Nonadaptive Personality test (SNAP; Clark, 1993) and found OCPD to be related to many traits commonly found in workaholics, including positive relationships with conscientiousness and neuroticism (Burke, Matthiesen, \& Pallesen, 2006), anxiousness (Robinson, 1996), achievement striving (McMillan et al., 2001), and negative temperament (Clark et al., 2010). Based on their assessment, Samuel and Widiger (2010) concluded, "workaholism appears to be a core trait of obsessive-compulsive personality disorder" (p. 331).

\section{Current Study}

The WAQ was created and validated to expand upon the efforts of others in developing an instrument that can be effective in identifying workaholism. First, it was administered to a heterogeneous sample, which makes the findings more generalizable to the entire workforce, not just to a specific occupation or type of organization. By collecting data from a heterogeneous population using both the WAQ and the WART, we are creating and validating a new measure of workaholism, as well as investigating the validity of the WART. Another reason the WART was specifically chosen for inclusion in this study, as opposed to the WorkBat, is that Robinson's (1989) definition of workaholism (i.e., an 
addiction leading to compulsive work behavior that can disrupt a workaholic's health and relationships) is more congruent with the conceptualization of workaholism as measured by the WAQ.

Second, the current study advances the workaholism literature by creating a more comprehensive instrument that includes items that directly tap into work-life imbalance, a typical symptom of workaholism. In the term work-life imbalance, "imbalance" is an occupational stressor based on lost resources of time, energy, and feelings toward work and personal life (Fisher, Bulger, \& Smith, 2009). Kirchmeyer (2000) viewed work-life balance as the even distribution of time, energy, and commitment across all life domains. The main source of negative consequences in other addictions is typically the use of the substance itself (e.g., one can overdose on many illegal, addictive substances), but the disruption workaholism causes in one's personal life is the key link between this construct and negative consequences (Porter, 1996). Therefore, the inclusion of items that measure the degree to which work disrupts one's life beyond work (i.e., work-life imbalance) is vital in a measure of workaholism.

Establishing construct validity is paramount when developing a new measure - essentially, the creators of a measure must demonstrate that the measure evaluates what they espouse it to evaluate. There are several different ways to establish construct validity (Bagozzi, Yi, \& Phillips, 1991), all of which highlight the importance of testing the convergent and discriminant validity of the new measure. Convergent validity is the degree to which a measure correlates well with an existing, valid measure of the same construct. Discriminant validity is the extent to which measures of different constructs are distinct - measures of two theoretically different constructs should not be related. In the current study, we also examined the WAQ's concurrent validity, which can be demonstrated by showing that a measure correlates well with a construct it should be related to theoretically. In sum, the validity of a measure can be established by empirically showing that it is related to an existing measure of the same construct (convergent validity), is related to a construct that it should be theoretically related to (concurrent validity), and is not related to a construct that it should not be theoretically related to (discriminant validity).

AC and NC should not correlate with workaholism because both are rooted in affect and workaholism is shown by behavior, demonstrating the WAQ's discriminant validity.

Hypothesis $1 a(\mathrm{H} 1 \mathrm{a})$ : The WAQ and WART will not correlate with AC.

Hypothesis $1 b(\mathrm{H} 1 \mathrm{~b})$ : The WAQ and WART will not correlate with NC.

Conversely, CC should correlate positively with workaholism because it is fueled by low selfesteem, building on the WAQ's concurrent validity. The correlation between the WAQ and CC is expected to be greater than Cohen's (1992) benchmark for small $(\rho=.1)$.

Hypothesis 1c (H1c): The WAQ and WART will positively correlate with CC, with $\rho>.1$.

OCPD is a multidimensional construct that predicts workaholism and contains similar facets - $\mathrm{a}$ positive correlation between the WAQ and OCPD will demonstrate the WAQ's concurrent validity. The correlation between the WAQ and OCPD is expected to be greater than Cohen's benchmark for small ( $\rho$ $=.1$ ).

Hypothesis 2 (H2): The WAQ and WART will positively correlate with OCPD, with $\rho>.1$.

It is predicted that in a heterogeneous sample of participants, the WAQ will correlate positively with the WART, showing the WAQ's convergent validity. The correlation between the WAQ and WART is expected to be greater than Cohen's benchmark for large $(\rho=.5)$.

Hypothesis 3 (H3): The correlation between the WAQ and WART will be positive, with $\rho>.5$. 


\section{Method}

The research was conducted in two phases. First, items were created for a new measure of workaholism. Second, the new measure was compared with the WART and validated in terms of discriminant, concurrent, convergent, and content validity.

\section{Item Development}

Items for the WAQ were developed based on a literature review of past workaholism research, conducted by one of the research investigators. Consistent with the main themes from previous definitions of workaholism, a measure addressing certain key components was created. First, workaholism is conceptualized as an addiction that leads to negative outcomes. Second, workaholics have an internal pressure to work that is independent of pressure from external sources (work drive). Finally, the workaholic's preoccupation with work results in the exclusion of personal activities (work-life imbalance).

The new measure was originally a 34-item behavioral checklist developed by one of the research investigators for pedagogical purposes utilized at a workshop on workaholism. To create the new workaholism measure, the checklist items were transformed into statements, with scale anchors ranging from 1 (strongly disagree) to 5 (strongly agree).

After the statements were created and the scale anchors were determined, the new measure (i.e., the WAQ), the WART, and measures of organizational commitment and OCPD were administered. An item analysis was conducted to identify any items that did not contribute well to the reliability of the measure; those items were removed from the WAQ. A reliability analysis was done on all measures, most importantly the WAQ, to ensure they had adequate internal consistency. Finally, an exploratory factor analysis was conducted on the WAQ items to identify its factor structure. The relationships among the WAQ, the WART, OCPD, and organizational commitment were then examined to demonstrate construct validity.

\section{Validation}

Cronbach and Meehl's (1955) hallmark paper on construct validity discusses how using correlations to demonstrate validity is appropriate. They state, "Many types of evidence are relevant to construct validity, including content validity, interitem correlations, intertest correlations, test-"criterion" correlations, studies of stability over time, and stability under experimental intervention." They move on to say, "High correlations and high stability may constitute either favorable or unfavorable evidence for the proposed interpretation, depending on the theory surrounding the construct" (p. 300). Therefore, to establish the argument for the WAQ as a valid measure, correlations among the WAQ, OCPD, and CC were examined to determine concurrent validity. Furthermore, correlations among the WAQ, AC, and NC were examined to determine discriminant validity. In addition, the relationship between the WAQ and the WART was investigated to demonstrate convergent validity. Finally, to demonstrate if the WAQ has adequate content validity, graduate students were asked to identify the WAQ items within a pool that included additional items.

\section{Participants}

Participants worked in different organizational settings and professional fields (e.g., medicine, law, education), primarily from the Southeastern United States. A participant's survey was included in the data analysis if $90 \%$ of the questions in each scale had been answered; 188 out of 219 participants met this criterion, providing power of $98 \%$ for detecting medium-sized associations. The sample included participants ranging from: 25 years and under (14\%), 26-30 (43\%), 31-35 (15\%), 36-40 (8\%), and over 40 years $(20 \%)$. The sample included women $(66 \%)$ and men $(34 \%)$, of which sixty percent were single and 
forty percent were married. Over two-thirds of the participants (69\%) did not have a child. The most represented racial group was Caucasian Americans (87\%), followed by Asian/Pacific Islanders (8\%), African Americans (3\%), Latin Americans (1\%), and Native Americans (1\%). Participants held nonmanagement positions (43\%), lower management positions (15\%), middle management positions (21\%), senior management positions (9\%), and professor positions (12\%). Position tenure for participants was as follows: working in current position for less than a year (21\%), from 1-2 years (23\%), from 3-4 years (24\%), from 5-9 years (15\%), from 10-14 years (6\%), and for 15 years or more (11\%). Participants' annual income ranged from: under $\$ 20,000(3 \%), \$ 20,000-\$ 39,999(18 \%), \$ 40,000-\$ 59,999(34 \%)$, $\$ 60,000-\$ 79,999$ (22\%), \$80,000-\$99,999 (7\%), \$100,000-\$149,999 (10\%), and \$150,000 and over (6\%). Additionally, participants worked a wide range of hours per week: 35 hours or less (8\%), 36-40 (22\%), 41-45 (25\%), 46-50 (16\%), 51-55 (13\%), 56-60 (8\%), and more than 60 hours per week (8\%).

\section{Procedure}

Contacts of the experimenters were sent a recruitment email outlining the study's purpose, duration of the survey, criteria for taking the survey (i.e., working professional who is not self-employed nor in the military), and the online survey link. Participants were encouraged to forward the recruitment email to coworkers and other professional contacts.

The informed consent form was presented at the onset and participants had to confirm they read and understood it before being granted access to the survey. The form explained their participation was completely voluntary and they would not be monetarily compensated. It also assured participants of their right to confidentiality, anonymity, and to withdraw from the survey at any point without penalty.

\section{Measures}

WAQ. The WAQ is a 29-item self-report measure of workaholism scored on a 5-point Likert scale, ranging from 1 (strongly disagree) to 5 (strongly agree), with higher scores indicating higher levels of workaholism. Sample items include, "I enjoy spending evenings and weekends working" and "I often obsess about goals or achievements at work." Cronbach's alpha was .934 in the current study.

WART. Robinson's (1999) WART is a 25-item self-report measure scored on a 4-point scale, ranging from 1 (very untrue of $m e$ ) to 4 (very true of $m e$ ), with higher scores indicating higher levels of work addiction. Sample items include, "I feel guilty when I am not working on something" and "I spend more time working than socializing with friends, on hobbies, or on leisure activities." Cronbach's alpha was .895.

Organizational Commitment. Meyer, Allen, and Smith's (1993) 6-item scales for AC, CC, and $\mathrm{NC}$ were scored on a 7-point scale, ranging from 1 (strongly disagree) to 7 (strongly agree), with higher scores indicating higher levels of that type of commitment. A sample AC item includes, "This organization has a great deal of personal meaning for me." A sample CC item includes, "I feel that I have too few options to consider leaving this organization." A sample NC item includes, "I would not leave my organization right now because I have a sense of obligation to the people in it." Cronbach's alphas were .88 (AC), .80 (CC), and $.90(\mathrm{NC})$.

OCPD. The Schedule for Nonadaptive and Adaptive Personality (SNAP; Clark, 1993) is a 375item true-false measure of personality disorders and related trait pathology. The SNAP's 25-item OCPD scale was used in the current study. The six diagnostic criteria from the DSM-IV-TR (American Psychiatric Association, 2000) covered in the OCPD scale are "preoccupation with details," "perfectionism," "workaholism," "moral inflexibility," "inability to discard worthless objects," and "reluctancy to delegate." Cronbach's alpha was .67. 


\section{Results}

After culling four items with low item-total correlations and one item that produced multicollinearity, the 29-item measure had a Cronbach's alpha of .934 (see Appendix A) and all items had VIF values of less than 5. An exploratory factor analysis using the principle-axis factor extraction was conducted to determine the factor structure of the WAQ. Both parallel analysis and Velicer's MAP test (O'Connor, 2000, 2012) indicated a five-factor structure. The WAQ was conceived as multidimensional, with the various dimensions being nonorthogonal. Accordingly, we employed an oblique rotation. Such a rotation created five factors with sums of squared loadings ranging from 3.7 to 8.3, and the clustering of items into factors seemed easily interpretable (see Table 1). The correlations between factors ranged from .24 to .48 (see Table 2). Although a multi-factor solution was tenable with rotation, this structure should be considered preliminary at this point, pending confirmatory work. Accordingly, only the total scores were used for the validity analyses.

Table 1. Oblique Factor Analysis of the WAQ

\begin{tabular}{|c|c|c|}
\hline Item & Greatest $\mid$ Beta $\mid$ & Factor \\
\hline 28. I have difficulty maintaining friendships. & .72 & 1, Work-Life Conflict \\
\hline 24. My work often seems to interfere with my personal life. & .67 & 1 \\
\hline 29. I have difficulty maintaining intimate relationships. & .66 & 1 \\
\hline 26. I often miss out on important personal activities because of work demands. & .62 & 1 \\
\hline 25. I often put issues in my personal life "on hold" because of work demands. & .62 & 1 \\
\hline 23. I experience conflict with my significant other or with close friends. & .60 & 1 \\
\hline 14. I find myself unable to enjoy other activities because of my thoughts of work. & .47 & 1 \\
\hline 27. I find it difficult to schedule vacation time for myself. & .46 & 1 \\
\hline 6. I constantly feel too tired after work to engage in non-work activities. & .45 & 1 \\
\hline 12. I frequently have work-related insomnia. & .45 & 1 \\
\hline 1. I feel stressed out when dealing with work issues. & .33 & 1 \\
\hline 19. I frequently check over my work many times before I finish it. & .66 & 2, Work Perfectionism \\
\hline 20. I ask others to check my work often. & .56 & 2 \\
\hline 22. It takes me a long time to finish my work because it must be perfect. & .50 & 2 \\
\hline 21. I frequently feel anxious or nervous about my work. & .50 & 2 \\
\hline 18. I often obsess about goals or achievements at work. & .41 & 2 \\
\hline
\end{tabular}


Table 1. Oblique Factor Analysis of the WAQ (continued)

\begin{tabular}{|c|c|c|}
\hline Item & Greatest $\mid$ Beta| & Factor \\
\hline 8. I prefer to work excessive hours, preferably 60 hours or more per week. & .66 & 3, Work Addiction \\
\hline 11. I enjoy spending evenings and weekends working. & .63 & 3 \\
\hline 13. I feel very addicted to my work. & .58 & 3 \\
\hline 7. I think about work constantly. & .42 & 3 \\
\hline 9. I have a need for control over my work. & .29 & 3 \\
\hline 17. People would describe me as being impatient and always in a hurry. & .67 & 4, Unpleasantness \\
\hline 15. I consider myself to be a very aggressive person. & .62 & 4 \\
\hline 16. I get irritated often with others. & 60 & 4 \\
\hline 10. I have a need for control over others. & .39 & 4 \\
\hline 3. I feel anxious when I am not working. & .94 & 5, Withdrawal Symptoms \\
\hline 2. I feel guilty when I am not working. & .85 & 5 \\
\hline 4. I feel bored or restless when I am not working. & .55 & 5 \\
\hline 5. I am unable to relax at home due to preoccupation at work. & .44 & 5 \\
\hline
\end{tabular}

Table 2. Correlations among the Factors $(N=188)$

\begin{tabular}{ccccc}
\hline Factor & 1 & 2 & 3 & 4 \\
\hline 2 & .31 & & & \\
3 & .29 & .24 & & \\
4 & .30 & .28 & .26 & \\
5 & .48 & .47 & .38 & .28 \\
\hline
\end{tabular}

Fourteen graduate students were asked to identify the WAQ's 30 items out of a pool of 40 items. Items from the WAQ were correctly identified $89 \%$ of the time, which demonstrates adequate content validity.

Table 3 presents descriptive statistics and intercorrelations. Neither the WAQ nor the WART was significantly correlated with $\mathrm{AC}$ and $\mathrm{NC}$, demonstrating discriminant validity and supporting $\mathrm{H} 1 \mathrm{a}$ and H1b respectively. Both the WAQ and the WART were significantly correlated with CC, with the confidence interval for $\rho$ excluding values of small size, 95\% CI [.13, .40], demonstrating concurrent validity and supporting H1c. Furthermore, the WAQ and the WART were significantly correlated with OCPD, with the confidence interval for $\rho$ excluding values of large size or less, 95\% CI $[.55, .72]$ showing concurrent validity and supporting H2. However, the WAQ and the WART did not differ significantly with respect to their correlations with CC, Steiger's $z=.75, p=.44$; OCPD, Steiger's $z=$ $.00, p=1.00 ;$ AC, Steiger's $z=1.46, p=.14$; and NC, Steiger's $z=.55, p=.58$. Additionally, the WAQ significantly correlated with the WART $(r=.72)$, with the confidence interval for $\rho$ excluding values of large size or less, 95\% CI [.64, .78], demonstrating convergent validity and supporting H3. Finally, all scales had acceptable reliability coefficients (Nunnally \& Bernstein, 1994) and were similar to those found in previous research (e.g., Meyer et al., 1993; Samuel \& Widiger, 2010). Cronbach's alpha was significantly greater for the WAQ than for the WART, Feldt $W=.629, p<.001$. 
Table 3. Correlations and Descriptives $(N=188)$

\begin{tabular}{l|cccccc}
\hline Variable & WAQ & WART & AC & CC & NC & OCPD \\
\hline WAQ & .93 & & & & & \\
WART & $.72 * *$ & .90 & & & & \\
AC & -.06 & .02 & .88 & & & \\
CC & $.27 * *$ & $.23 * *$ & -.11 & .80 & & \\
NC & .06 & .03 & $.75^{* *}$ & .07 & .90 & \\
OCPD & $.64 * *$ & $.64 * *$ & -.07 & $.25 * *$ & .01 & .73 \\
\hline
\end{tabular}

\begin{tabular}{l|cccccc}
\hline $\begin{array}{l}\text { Range of } \\
\text { Possible } \\
\begin{array}{l}\text { Scores } \\
\text { Range for }\end{array}\end{array}$ & $1-5$ & $1-4$ & $1-7$ & $1-7$ & $1-7$ & $0-1$ \\
Current Data & $1.03-4.17$ & $1.21-3.58$ & $1.00-7.00$ & $1.17-7.00$ & $1.00-7.00$ & $.16-1.00$ \\
$M$ & & & & & & \\
SD & 2.49 & 2.56 & 4.38 & 4.18 & 4.08 & .53 \\
\hline
\end{tabular}

Note. Entries on the main diagonal are Cronbach's alpha. WAQ, Workaholism Analysis Questionnaire; WART, Work Addiction Risk Test; AC, Affective Commitment; CC, Continuance Commitment; NC, Normative Commitment; OCPD, Obsessive-Compulsive Personality Disorder. ${ }^{*} p<.05 * * p<.001 .\left|g_{l}\right|<$ .41 and $\left|g_{2}\right|<.79$ for all variables.

\section{Discussion}

The purpose of the current study was to enhance the attempts of others by developing a measure - the WAQ - to identify workaholism effectively. Moreover, given that one of the primary issues of the WART is it having been studied with homogeneous samples, both the WAQ and the WART were psychometrically tested on a heterogeneous working population, making the findings more generalizable to the entire workforce and not just to a specific occupation or type of organization. Hence, not only did we create and validate a new measure of workaholism, our research also evaluated the validity of the WART.

Findings indicated that the WAQ is an adequate measure of workaholism with strong internal reliability; in fact, Cronbach's alpha was significantly greater for the WAQ than for the WART.

Additionally, the WAQ measures work drive and the disruption it causes to work-life balance; work drive is the key facet of workaholism because it is most closely related to poor physical and psychological health. Further, the WAQ provides a more complete measure of workaholism with its inclusion of items that associate with work-life imbalance, a common symptom of workaholism and other addictive disorders.

As predicted, the WAQ positively correlated with the WART $(\rho>.5)$, demonstrating convergent validity. The strength of their correlation suggests there is substantial overlap between them. The WART has five factors, of which the Compulsive Tendencies scale contains the most items and has the strongest validity for identifying workaholism (Flowers \& Robinson, 2002); high work drive, a cognitive trait expressed through compulsive behavior, is one of the focal points of the WAQ. The WART includes items about relationships, although relationships and work-life imbalance do not serve as focal points of 
the WART like they do in the WAQ. Perhaps the WAQ strongly correlated with the WART due to these similarities.

The pattern of relationships found between the WAQ and the organizational commitment scales of AC and NC were supported, demonstrating discriminant validity. As predicted, the WAQ and the WART did not significantly correlate with AC. AC measures people's emotional attachment to their organization; however, workaholics are committed to work (Naughton, 1987). In other words, workaholics do not have to be emotionally attached to their organization to feel a compulsion to work. Thus, some workaholics strongly identify with their organization while others do not, but neither of these circumstances occurs more frequently than the other.

As expected, the WAQ and the WART did not significantly correlate with NC. One explanation for this finding is NC's conceptual and empirical ties to AC, which has led some researchers to conclude they are inseparable (Ko, Price, \& Mueller, 1997) — indeed, NC correlated extremely well with AC in the current study, replicating a finding common in the organizational commitment research (Allen \& Meyer, 1996). The conceptual and empirical overlap between NC and AC in this study and in previous research suggests that workaholism should not correlate well with the NC scale.

As predicted, the WAQ and the WART correlated positively with CC. Scott et al. (1997) proposed that achievement-oriented workaholics are high performers that attain substantial organizational side-bets throughout their career and want to hold on to these benefits, which increases CC. Also, workaholics may have an external locus of control due to their low self-esteem, which is a personality characteristic that can cause people to perceive fewer alternatives to their current employment situation (Spector, 1982), thus increasing their feelings of CC. Hence, workaholics, who are achievement-oriented, fear losing their side-bets more than the average employee and those with a low self-esteem are more likely to perceive a lack of alternatives to their current position - both of these circumstances are common in workaholics and have been shown to increase CC.

OCPD has ties to workaholism and is linked to many psychological and physical ailments (Pollak, 1979). As expected, the WAQ and the WART correlated positively with OCPD. OCPD might be key in understanding how workaholism leads to a host of negative outcomes - Scott et al. (1997) proposed it is the obsessive-compulsive tendencies of workaholics that lead to consequences such as higher stress, less job/life satisfaction, and lower job performance. People with OCPD frequently experience compulsions driven by obsessions, which is similar to people with high work drives who cannot stop thinking about work, to the point where it interferes with life outside work. Thus, the drive component of workaholism is the component most closely linked to OCPD; this connection has been empirically shown (Aziz et al., 2010; McMillan et al., 2002).

To better understand how the workaholism measures relate to OCPD, correlations were run between the total WART, the total WAQ, and the individual OCPD items. Fittingly, the WAQ correlated stronger (i.e., a difference of .1 between correlation coefficients was considered large enough to be noteworthy) than the WART with three OCPD items assessing work interference with personal life, which is congruent with the main themes of the WAQ. On the other hand, the WART correlated better with two OCPD items measuring reluctance to delegate.

In sum, the goal of the study was to create and validate a new measure of workaholism using a heterogeneous, working-professional sample. The WAQ was found to be a reliable measure demonstrating: 1) convergent validity by correlating significantly with the WART; 2) concurrent validity by correlating significantly with $\mathrm{CC}$ and OCPD; 3 ) discriminant validity by not correlating significantly with AC and NC; and 4) content validity. Our research also represents an investigation of the validity of both the WAQ and the WART.

\section{Limitations}

Despite the significant findings, some limitations are noted. Personal contacts of the experimenters were directly contacted, who in turn recruited additional working professionals. This recruitment method creates a "snowball" effect that is neither a sample of convenience nor a completely 
random sample and has been used by other researchers (Brotheridge \& Lee, 2002; Lim \& Lee, 2011). Such methods provide quality data comparable to traditional forms of recruiting (Smith, Tisak, Hahn, \& Schmieder, 1997).

Another limitation is the use of self-report measures. Although self-reports are convenient, inexpensive, and easy to administer, their use might have led to response distortion among participants given that people typically have inaccurate opinions of themselves (Spector, 1994). Nonetheless, given that perceptions of psychological constructs lie in the eye of the beholder, the hypotheses were appropriately assessed by asking employees to indicate their own attitudes.

\section{Implications}

Despite the rise in awareness to workaholism's detrimental effects, it is still encouraged in organizations. For workaholism to be taken seriously, researchers must decide on both a single definition and a measure that highlights the negative consequences of workaholism. High work drive is the facet of workaholism with the strongest ties to negative psychological outcomes (Burke, 2000; Burke \& Fiksenbaum, 2009a). Moreover, work-life imbalance is both a key component and a symptom of workaholism, as with other addictions, which causes stress along with other negative consequences (Burke, 2000). The WAQ assesses workaholism more accurately than existing measures by focusing on high work drive and work-life imbalance. Further, the WorkBat and the WART have unstable factor structures and their psychometric properties have been called into question in multiple studies. In light of the current study's findings and past research on existing workaholism measures, we assert that the WAQ is a reliable measure that should be used in future studies to validly evaluate workaholism.

Organizations can use the WAQ to identify employees with workaholic tendencies and apply appropriate organizational interventions to mitigate the negative outcomes caused by high work drive. On that note, this study has solidified workaholism's strong relationship to OCPD. Psychologists have examined the causes of OCPD since the $20^{\text {th }}$ century (Freud, 1908/1953). A link to such an old, established disease potentially opens the door for workaholism to therapeutic treatments (e.g., cognitivebehavioral therapy) that have been successful in alleviating OCPD tendencies. More systemic interventions to alleviate widespread workaholism, such as changes in organizational culture that promote living a balanced lifestyle to employees, have been discussed in recent workaholism literature as well (Burke \& Fiksenbaum, 2009b).

\section{Conclusions}

Workaholism, as assessed by the WAQ, is characterized by a strong internal drive to work which causes significant disruption to one's personal life and relationships. Both the WART and the WorkBat have made valuable contributions to the workaholism literature, however, the WAQ is clearly a psychometrically sound instrument that more precisely measures workaholism and further strengthens the ties between workaholism and work-life imbalance and addiction. This effort to refocus the definition of workaholism as an addiction and measure it as such may help clear up the confusion concerning workaholism in the academic literature and raise awareness amongst management in corporate America concerning this detrimental illness. 


\section{Appendix A \\ Workaholism Analysis Questionnaire}

Please answer the following questions concerning how you feel about various aspects of your work by choosing one of the five alternatives that best reflects your answer.

\begin{tabular}{|c|c|c|c|c|}
\hline 1 & 2 & 3 & 4 & 5 \\
\hline $\boldsymbol{\nabla}$ & $\boldsymbol{\nabla}$ & $\boldsymbol{\nabla}$ & $\boldsymbol{\nabla}$ & $\boldsymbol{\nabla}$ \\
\hline Strongly & & & & Strongly \\
\hline Disagree & Disagree & Neutral & Agree & Agree \\
\hline
\end{tabular}

Item

Corrected

Item-Total

Correlation

1. I feel stressed out when dealing with work issues.

2. I feel guilty when I am not working.

3. I feel anxious when I am not working.

4. I feel bored or restless when I am not working.

5. I am unable to relax at home due to preoccupation at work.

6. I constantly feel too tired after work to engage in non-work activities.

7. I think about work constantly.

8. I prefer to work excessive hours, preferably 60 hours or more per week.

9. I have a need for control over my work.

10. I have a need for control over others.

11. I enjoy spending evenings and weekends working.

12. I frequently have work-related insomnia.

13. I feel very addicted to my work.

14. I find myself unable to enjoy other activities because of my thoughts of work.

15. I consider myself to be a very aggressive person. 
16. I get irritated often with others.

17. People would describe me as being impatient and always in a hurry. $\quad .490$

18. I often obsess about goals or achievements at work. 627

19. I frequently check over my work many times before I finish it. 379

20. I ask others to check my work often. $\quad 297$

21. I frequently feel anxious or nervous about my work. $\quad .610$

22. It takes me a long time to finish my work because it must be perfect. $\quad .578$

23. I experience conflict with my significant other or with close friends. $\quad .564$

24. My work often seems to interfere with my personal life. $\quad .760$

25. I often put issues in my personal life "on hold" because of work $\quad .772$ demands.

26. I often miss out on important personal activities because of work demands.

27. I find it difficult to schedule vacation time for myself.

28. I have difficulty maintaining friendships. $\quad .558$

29. I have difficulty maintaining intimate relationships.

.479 


\section{References}

Allen, N. J., \& Meyer, J. P. (1990). The measurement and antecedents of affective, continuance and normative commitment to the organization. Journal of Occupational Psychology, 63, 1-18.

Allen, N. J., \& Meyer, J. P. (1996). Affective, continuance, and normative commitment to the organization: An examination of construct validity. Journal of Vocational Behavior, 49, 252-276.

American Psychiatric Association. (2000). Diagnostic and statistical manual of mental disorders (4th ed., text rev.). Washington, DC: Author.

Andreassen, C. S., Ursin, H., \& Eriksen, H. R. (2007). The relationship between strong motivation to work, 'workaholism', and health. Psychology \& Health, 22, 615-629.

Aziz, S., Adkins, C. T., Walker, A. G., \& Wuensch, K. L. (2010). Workaholism and work-life imbalance: Does cultural origin influence the relationship? International Journal of Psychology, 45, 72-79.

Bagozzi, R. P., Yi, Y., \& Phillips, L. W. (1991). Assessing construct validity in organizational research. Administrative Science Quarterly, 36, 421-458.

Becker, H. S. (1960). Notes on the concept of commitment. American Journal of Sociology, 66, 32-40.

Bergman, M. (2006). The relationship between affective and normative commitment: review and research agenda. Journal of Organizational Behavior 27, 645-663.

Bonebright, C. A., Clay, D. L., \& Ankenmann, R. D. (2000). The relationship of workaholism with worklife conflict, life satisfaction, and purpose in life. Journal of Counseling Psychology, 47, 469-477.

Brady, B. R., Vodanovich, S. J., \& Rotunda, R. (2008). The impact of workaholism on work-family conflict, job satisfaction, and perception of leisure activities. The Psychologist-Manager Journal, 11, 241-263.

Brotheridge, C. M., \& Lee, R. T. (2002). Testing a conservation of resources model of the dynamics of emotional labor. Journal of Occupational Health Psychology, 7, 57-67.

Buelens, M., \& Poelmans, S. A. Y. (2004). Enriching the Spence and Robbins' typology of workaholism: Demographic, motivational, and organizational correlates. Journal of Organizational Change Management, 17, 440-458.

Burke, R. J. (2000). Workaholism in organizations: Psychological and physical well-being consequences. Stress and Health, 16, 11-16.

Burke, R. J., \& Fiksenbaum, L. (2009a). Work motivations, work outcomes, and health: Passion versus addiction. Journal of Business Ethics, 84, 257-263.

Burke, R. J., \& Fiksenbaum, L. (2009b). Work motivations, satisfactions, and health among managers: Passion versus addiction. Cross-Cultural Research, 43, 349-365.

Burke, R. J., Matthiesen, S. B., \& Pallesen, S. (2006). Personality correlates of workaholism. Personality and Individual Differences, 40, 1223-1233.

Burke, R. J., Richardsen, A. M., \& Martinussen, M. (2002). Psychometric properties of Spence and Robbins' measure of workaholism components. Psychological Reports, 91, 1098-1104.

Clark, L.A. (1993). Schedule for Nonadaptive and Adaptive Personality (SNAP). Minneapolis: University of Minnesota Press.

Clark, M. A., Lelchook, A. M., \& Taylor, M. L. (2010). Beyond the big five: How narcissism, perfectionism, and dispositional affect relate to workaholism. Personality and Individual Differences, 48, 786-791.

Cohen, J. (1992). A power primer. Psychological Bulletin, 112, 155-159.

Cronbach, L. J., \& Meehl, P. E. (1955). Construct validity in psychological tests. Psychological Bulletin, $52,281-302$.

Ersoy-Kart, M. (2005). Reliability and validity of the workaholism battery (Work-BAT): Turkish form. Social Behavior and Personality, 33, 609-617.

Fisher, G. G., Bulger, C. A., \& Smith, C. S. (2009). Beyond work and family: A measure of work/nonwork interference and enhancement. Journal of Occupational Health Psychology, 14, 441-456. 
Flowers, C. P., \& Robinson, B. (2002). A structural and discriminant analysis of the Work Addiction Risk Test. Educational and Psychological Measurement, 62, 517-526.

Freud, S. (1953). Character and anal eroticism. In J. Strachey (Ed. and Trans.), The standard edition of the complete psychological works of Sigmund Freud (Vol. 9, pp. 169-175). London, England: Hogarth. (Original work published 1908)

Griffiths, M. (2005). Workaholism is still a useful construct. Addiction Research and Theory, 13, 97-100.

Hackett, R. D., Bycio, P., \& Hausdorf, P. A. (1994). Further assessments of Meyer and Allen's (1991) three-component model of organizational commitment. Journal of Applied Psychology, 79, 1523.

Harpaz, I., \& Snir, R. (2003). Workaholism: Its definition and nature. Human Relations, 56, 291-319.

Kanai, A., Wakabayashi, M., \& Fling, S. (1996). Workaholism among employees in Japanese corporations: An examination based on the Japanese version of the workaholism scales. Japanese Psychological Research, 38, 192-203.

Kirchmeyer, C. (2000). Work-life initiatives: Greed or benevolence regarding workers' time. In C. L. Cooper and D. M. Rousseau (Eds.), Trends in organizational behavior (Vol. 7, pp. 79-93). West Sussex, UK: Wiley.

Ko, J. W., Price, J. L., \& Mueller, C. W. (1997). Assessment of Meyer and Allen's three-component model of organizational commitment in South Korea. Journal of Applied Psychology, 82, 961973.

Lim, S. \& Lee, A. (2001). Work and nonwork outcomes of workplace incivility: Does family support help? Journal of Occupational Health Psychology, 16, 95-111.

McMillan, L. H. W., Brady, E. C., O’Driscoll, M. P., \& Marsh, N. V. (2002). A multifaceted validation study of Spence and Robbins' (1992) Workaholism Battery. Journal of Occupational and Organizational Psychology, 75, 357-368.

McMillan, L. H. W., O’Driscoll, M. P., Michael, P., Marsh, N. V., \& Brady, E. C. (2001). Understanding workaholism: Data synthesis, theoretical critique, and future design strategies. International Journal of Stress Management, 8, 69-91.

Meyer, J. P., Allen, N. J., \& Smith, C. A. (1993). Commitment to organizations and occupations: Extension and test of a three-component conceptualization. Journal of Applied Psychology, 78, 538-551.

Naughton, T. J. (1987). A conceptual view of workaholism and implications for career counseling and research. The Career Development Quarterly, 35, 180-187.

Ng, T. W. H., Sorensen, K. L., \& Feldman, D. C. (2007). Dimensions, antecedents, and consequences of workaholism: A conceptual integration and extension. Journal of Organizational Behavior, 28, 111-136.

Nunnally, J. C., \& Bernstein, I. H. (1994). Psychometric theory (3rd ed.). New York, NY: McGraw-Hill.

Oates, W. (1971). Confessions of a workaholic: The facts about work addiction. New York, NY: World Publishing.

O'Connor, B. P. (2000). SPSS and SAS programs for determining the number of components using parallel analysis and Velicer's MAP test. Behavior Research Methods, Instruments, \& Computers, $32,396-402$.

O'Connor, B. P. (2012). SPSS, SAS, and MATLAB programs for determining the number of components and factors. Retrieved from https://people.ok.ubc.ca/brioconn/nfactors/nfactors.html

Pollak, J. (1979). Obsessive-compulsive personality: A review. Psychological Bulletin, 86, 225-241.

Porter, G. (1996). Organizational impact of workaholism: Suggestions for researching the negative outcomes of excessive work. Journal of Occupational Health Psychology, 1, 70-84.

Porter, L. W., Steers, R. M., Mowday, R. T., \& Boulian, P. V. (1974). Organizational commitment, job satisfaction, and turnover among psychiatric technicians. Journal of Applied Psychology, 59, 603609.

Robinson, B. E. (1989). Work addiction. Deerfield Beach, FL: Health Communications. 
Robinson, B. E. (1996). The psychosocial and familial dimensions of work addiction: Preliminary perspectives and hypotheses. Journal of Counseling \& Development, 74, 447-452.

Robinson, B. E. (1999). The work addiction risk test: Development of a tentative measure of workaholism. Perceptual and Motor Skills, 88, 199-210.

Samuel, D. B., \& Widiger, T. A. (2010). A comparison of obsessive-compulsive personality disorder scales. Journal of Personality Assessment, 92, 232-240.

Scott, K. S., Moore, K. S., \& Miceli, M. P. (1997). An exploration of the meaning and consequences of workaholism. Human Relations, 50, 287-314.

Smith, C. S., Tisak, J., Hahn, S. E., \& Schmieder, R. A. (1997). The measurement of job control. Journal of Organizational Behavior, 18, 225-237.

Snir, R., \& Harpaz, I. (2009). Workaholism from a cross-cultural perspective. Cross-Cultural Research, 43, 303-308.

Spector, P. E. (1982). Behavior in organizations as a function of employees' locus of control. Psychological Bulletin, 91, 482-497.

Spector, P. E. (1994). Using self-report questionnaires in OB research: A comment on the use of a controversial method. Journal of Organizational Behavior, 15, 385-392.

Spence, J. T., \& Robbins, A. S. (1992). Workaholism: Definition, measurement, and preliminary results. Journal of Personality Assessment, 58, 160-178.

Taris, T. W., Schaufeli, W. B., \& Verhoeven, L. C. (2005). Workaholism in the Netherlands: Measurement and implications for job strain and work-nonwork conflict. Applied Psychology: An International Review, 54, 37-60. 